Article

\title{
Information Entropy for Evaluation of Wastewater Composition
}

\author{
Petr Praus \\ Institute of Environmental Technology, VŠB-Technical University of Ostrava, 17. listopadu 2172/15, \\ 70800 Ostrava, Czech Republic; petr.praus@vsb.cz
}

Received: 10 March 2020; Accepted: 7 April 2020; Published: 12 April 2020

\begin{abstract}
The composition of wastewaters collected during one year was evaluated based on the Shannon information entropy. Eleven physico-chemical parameters, biochemical oxygen demand (BOD), chemical oxygen demand (COD), total phosphorus (TP), total nitrogen (TN), total suspended solids (TSS), total dissolved salts (TDS), $\mathrm{pH}$, ammonium, phosphate, cyanide and phenol, were determined for their characterization. Entropy of the parameters calculated by means of their histograms decreased in the order: phosphate $>$ ammonium $>$ TDS $>$ TN $>\mathrm{pH}>\mathrm{BOD}>\mathrm{COD}>$ TSS $>$ TP $>$ phenol $>$ cyanide. Entropy weights of the parameters were calculated for the evaluation of wastewater composition by means of the entropy weighted index (EWI) defined according to the simple additive weighting (SAW) model. The EWI values were statistically processed by us to observe temporal wastewater composition changes and were verified by means of the principal component weighted index (PCWI). The EWI values were statistically analyzed by univariate statistics. The outlaying samples were also confirmed by multivariate analysis. The entropy-based approach allowed us to simply evaluate wastewater composition by means of one index instead of several parameters. The main advantage of EWI is the simple histogram-based calculation of entropy with no need of the normal distribution of the used parameters.
\end{abstract}

Keywords: information entropy; entropy weighted index; wastewater; evaluation; composition

\section{Introduction}

Real waters represent very complex systems containing organic and inorganic compounds, suspended solids, dissolved gases and different microorganisms. The physico-chemical properties can be characterized by several physical and chemical parameters and, therefore, the evaluation of water composition is a multidimensional problem. The parameters are of different magnitudes and scales, often mutually correlated and non-normally distributed. Some of them, such as chemical oxygen demand (COD), biochemical oxygen demand (BOD), electrical conductivity, total suspended solids (TSS) and total dissolved salts (TDS), characterize groups of similar compounds, while the others provide information about the concentrations (magnitudes) of individual compounds, such as anions and cations, heavy metals and many types of organic compounds.

The concept of entropy was introduced by R. J. E. Clausius (1822-1888) as a measure of dissipated and useless heat. With the development of thermodynamics in the 19th century, L. Boltzmann (1844-1906) defined entropy as a simple function of all possible ordered states $W$ as $S=k \ln W$, where $k$ is the Boltzmann constant, which means that entropy increases with higher disorder of a system. J. W. Gibbs (1839-1903) substituted the number of possible states with $n$ states with probabilities $p_{i}$ and derived the relationship $S=-k n \sum_{i=1}^{n} p_{i} \ln p_{i}$ which inspired C. E. Shannon's (1916-2001) concept of information entropy [1,2]. 
Unlike a majority of statistical methods based on normal distribution, entropy-based statistics is applicable to any distribution and even in cases when distributions are a priori unknown Maruyama, et al. [3]. It has been commonly used in physics [4,5], chemistry [6,7], informatics [8] and bioinformatics $[2,9,10]$, image processing [11,12], for the evaluation of business organisations [13], economics and finance processes [14] and company systems performance $[15,16]$. The concept has been used also for the analysis of urban ecosystems [17], environmental analysis [3,18-20], medical records [21-23] and in scientometrics [24,25]. Several papers focusing on river and groundwater quality assessment have been published as well [26-31]. However, to date no papers have been published on the topic of wastewaters evaluation.

The aim of this paper was to statistically evaluate raw wastewaters composition based on the concept of entropy in the information theory. The variance of wastewater parameters was expressed by entropy, and the changes of wastewater composition were evaluated by the single index composed of the parameters and their entropy weights. The entropy weighted index (EWI) values were verified by comparison with the values of principal component weighted index (PCWI) computed based on robust principal component analysis (RPCA) which was introduced recently [32].

\section{Materials and Methods}

\subsection{Sample Collection and Analysis}

The 343 wastewater samples were taken at an inlet of a biological wastewater treatment plant (BWWTP). The BWWTP was designed for the capacity of 640,000 population equivalents for the treatment of municipal and industrial wastewaters. Water analyses were performed according to ISO and EN standard procedures: EN 1899-1: 1998 (BOD), ISO 6060: 1989 (COD), EN ISO 6878: 2004 (total phosphorus (TP) and phosphate), EN 25663: 1993 (total nitrogen (TN)), EN 872: 1996 (TSS and TDS), ISO 10523: 2008 (pH), ISO 7150-1: 1984 (ammonium), ISO 6703-1: 1984 (cyanide) and ISO 6439: 1984 (phenol). The summary statistics of all samples is given in Table 1.

Table 1. Summary statistics of wastewater composition.

\begin{tabular}{ccccccccc}
\hline Param. & Mean & Median & St. Dev. & MAD & Min. & Max. & Skew. & Kurt. \\
\hline $\mathrm{NH}_{4}{ }^{+}$ & 35.5 & 36.1 & 10.7 & 8.90 & 5.56 & 68.9 & -0.033 & 3.42 \\
$\mathrm{BOD}$ & 194 & 191 & 70.6 & 54.9 & 25.7 & 625 & 1.25 & 8.79 \\
$\mathrm{COD}$ & 387 & 381 & 144 & 113 & 80.1 & 1350 & 2.14 & 14.2 \\
$\mathrm{Phenol}$ & 0.18 & 0.16 & 0.14 & 0.059 & 0.02 & 1.57 & 4.93 & 40.1 \\
$\mathrm{PO}_{4}{ }^{3-}$ & 5.22 & 5.13 & 2.63 & 3.32 & 0.526 & 12.1 & 0.044 & 1.97 \\
$\mathrm{CN}^{-}$ & 0.174 & 0.146 & 0.165 & 0.0786 & 0.016 & 2.03 & 6.40 & 63.2 \\
$\mathrm{TN}$ & 40.0 & 40.8 & 9.30 & 7.41 & 13.2 & 90 & 0.050 & 5.52 \\
$\mathrm{TSS}$ & 280 & 256 & 141 & 94.9 & 44 & 1665 & 3.61 & 31.0 \\
TP & 6.26 & 6.25 & 2.54 & 1.39 & 1.40 & 34.7 & 5.06 & 52.4 \\
pH & 7.74 & 7.75 & 0.188 & 0.178 & 6.89 & 8.22 & -0.623 & 5.21 \\
TDS & 706 & 730 & 129 & 91.9 & 276 & 1088 & -0.856 & 4.32 \\
\hline
\end{tabular}

Note: MAD is median absolute deviation. Except for $\mathrm{pH}$, the units of all parameters were $\mathrm{mg} / \mathrm{L}$.

\subsection{Entropy Calculation}

In general, information entropy $H_{j}$ of each variable $x_{j}$ (the number of variables is $m$ ) describing $n$ observations can be defined by Shannon's relationship [1] as

$$
H_{j}=-\sum_{i=1}^{n} p_{i, j} \ln p_{i, j}
$$


where $p_{i, j}$ is the probability of $x_{j}$ occurrence; it holds: $\sum_{i=1}^{n} p_{i, j}=1$. The maximal entropy is defined as $H_{j, \max }=\ln n$. The probabilities $p_{i, j}$ can be approximated with relative frequencies $f_{i, j}$ calculated using histograms for $N$ intervals as follows

$$
\bar{H}_{j}=-\sum_{i=1}^{N} f_{i, j} \ln f_{i, j}
$$

In analogy with the simple additive weighting (SAW) model [33], EWI describing composition of a water sample $i$ was calculated as

$$
E W I_{i}=\sum_{j=1}^{m} w_{j} \frac{x_{i, j}}{\mu_{j}}
$$

where $\mu_{j}$ is the mean of parameter $x_{j}$ calculated from $n$ samples and $w_{j}$ is the entropy weight. It holds: $\sum_{j=1}^{m} w_{j}=1$. The ratio $\frac{x_{i, j}}{\mu_{j}}$ compensates the different scales and units of the parameters and can be considered as a relative concentration. The entropy weights were calculated as

$$
w_{j}=\frac{1-h_{j}}{\sum_{j=1}^{m} 1-h_{j}}
$$

where

$$
h_{j}=\frac{\bar{H}_{j}}{H_{j, \max }}=\frac{1}{\ln n} \bar{H}_{j} .
$$

\subsection{Principal Component Analysis}

Principal component analysis looks for new latent variables of $n$ samples, which are statistically independent [34]. Each latent variable-principal component (PC) is a linear combination of $p$ variables $x_{i}$ and describes a different source of total variation

$$
X=T W^{T}+E
$$

where $\boldsymbol{X}(n \times m)$ is the data matrix, $\boldsymbol{T}(n \times p)$ and $\boldsymbol{W}(m \times p)$ are the matrix of principal components scores and loadings, respectively, and $\boldsymbol{E}(n \times m)$ is the residual matrix representing noise. Classical PCA can be performed by eigenvalue decomposition of a correlation matrix or singular value decomposition (SVD) of an original data matrix [35,36]. RPCA was performed by the eigenvalue decomposition of an estimated correlation matrix with the lowest possible determinant computed using a minimum covariance determinant (MCD) algorithm [37-39]. It was computed using a subroutine (mcdcov) in MATLAB (see below).

\subsection{Mahalanobis Distance}

The Mahalanobis distance of a variable $x_{i}$ can be computed as

$$
M D=\sqrt{(\mathbf{x}-\mu)^{T} \mathbf{C}^{-1}(\mathbf{x}-\mu)}
$$

where $\mu$ is the mean vector of $n$ variables $x_{i}, x$ is the row vector of variable $x_{i}$ and $C$ is the covariance matrix. The robust Mahalanobis distance of the variable $x_{i}$ can be computed as

$$
R M D=\sqrt{\left(\mathbf{x}-\mu_{M}\right)^{T} \sum^{-1}\left(\mathbf{x}-\mu_{M}\right)}
$$


where $x$ is the row vector of variable $x_{\mathrm{i},} \mu_{M}$ is the MCD estimation of location and $\Sigma$ is the MCD estimated covariance matrix. The MCD estimator is considered to be a highly robust estimator of multivariate location and scatter.

\subsection{Statistic Calculations}

An original data matrix of wastewater samples was processed in MS Excel. The MCD estimators were calculated by means of the LIBRA MATLAB Library [40] using MATLAB R2015b (MathWorks, USA). Statistical calculations were performed using the software packages QC.Expert (TriloByte, Czech Republic) and XLSTAT 2019 (Addinsoft, Boston, MA, USA). The data smoothing was performed by a fast Fourier transform (FFT) algorithm in the program OriginPro 9.0.0. (Origin Corporation, Northampton, MA, USA).

The data were standardized in order to avoid misclassifications arising from different orders of magnitude of variables. For this purpose, the data were mean $(\mu)$ centred and scaled by standard deviations $(\sigma)$ as $y=\frac{x-\mu}{\sigma}$.

\section{Results and Discussion}

\subsection{Entropy and Entropy Weights of Wastewater Parameters}

The raw wastewaters mixed from municipal and industrial ones were characterized by the 11 parameters listed in Table 1 . The wastewater data were standardized as mentioned above: the original parameters $x_{j}$ were scaled and centred to obtain the transformed parameters $y_{j}$ which were further used by us to approximate their density functions $p_{i, j}$ by relative frequencies $f\left(y_{i, j}\right)$ to be used in Equation (2). Two examples of histograms with the highest $\left(\mathrm{PO}_{4}{ }^{3-}\right)$ and lowest entropy $\left(\mathrm{CN}^{-}\right)$are shown in Figure 1 .
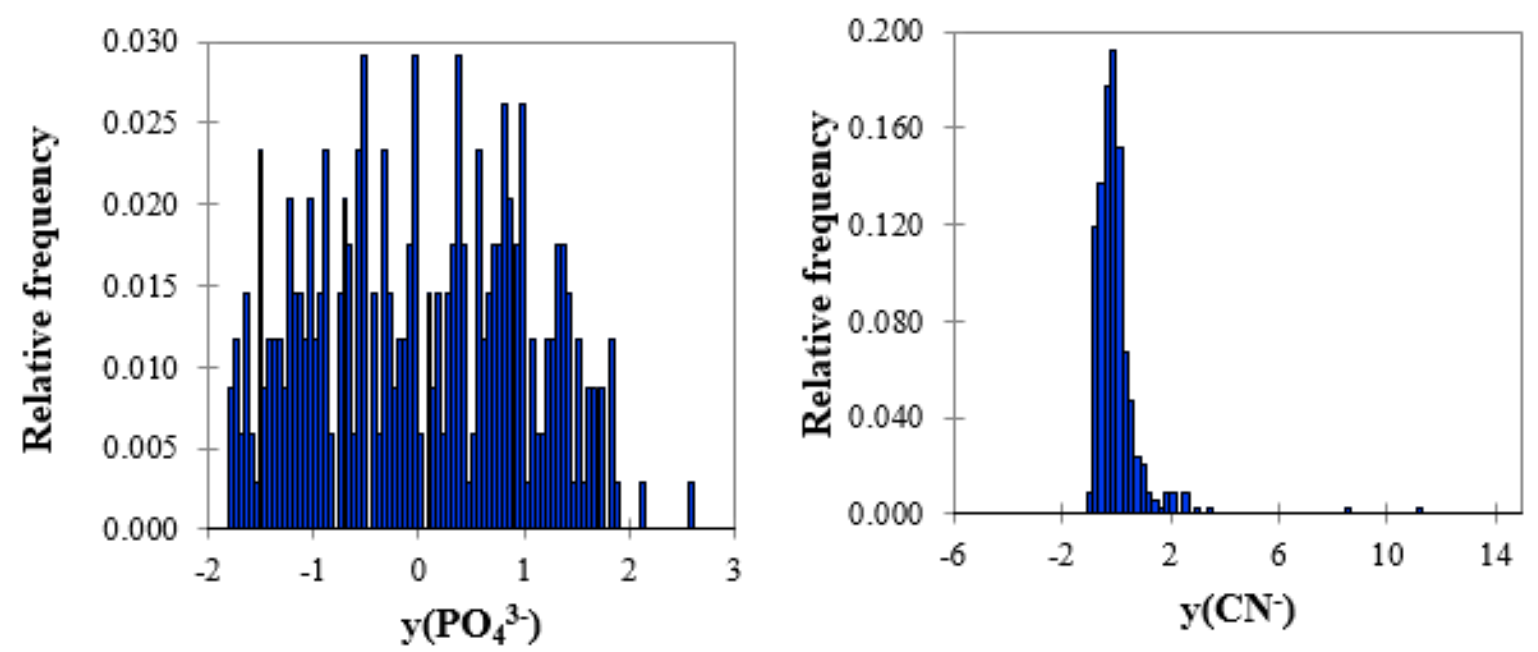

Figure 1. Histograms of phosphate and cyanide.

The entropy values summarized in Table 2 decreased in the sequence $\mathrm{PO}_{4}{ }^{3-}>\mathrm{NH}_{4}{ }^{+}>$TDS $>$ $\mathrm{TN}>\mathrm{pH}>\mathrm{BOD}>\mathrm{COD}>\mathrm{TSS}>\mathrm{TP}>$ phenol $>\mathrm{CN}^{-}$. Based on explanatory analysis, for example the P-P plot shown in Figure S1 (Supplementary Materials), the parameters were separated into two groups: the first group contained the parameters with higher entropy, such as $\mathrm{PO}_{4}{ }^{3-}, \mathrm{NH}_{4}{ }^{+}, \mathrm{TDS}, \mathrm{TN}$, $\mathrm{pH}, \mathrm{BOD}$ and COD, and the second one consisted of TSS, TP, phenol and $\mathrm{CN}^{-}$with lower entropy. It is obvious that entropy decreased with increasing kurtosis and skewness. The high values of kurtosis and skewness are typical for the variables, which changed in narrow intervals and existed in low magnitudes and, thus, their distributions were tailed. This is the case for the parameters in the second group. 
The parameters of the first group were of higher entropy, that is, higher uncertainty, documented by the higher median absolute deviation (MAD) values. From a practical point of view, they should be monitored more frequently than the others by, for instance, the continual determination of $\mathrm{pH}$, phosphate, ammonium, TN and COD. BOD and COD characterize mostly organic compounds, similar to $\mathrm{TN}$ and ammonium, which is the prevailing nitrogen form mostly resulting from hydrolysis of urea. Dissolved phosphate also enters wastewaters in the form of urea and detergents [41].

Table 2. Entropy and entropy weights of wastewater parameters.

\begin{tabular}{ccc}
\hline Parameter & Entropy & Entropy Weight \\
\hline $\mathrm{PO}_{4}{ }^{3-}$ & 4.196 & 0.0282 \\
$\mathrm{NH}_{4}{ }^{+}$ & 3.999 & 0.0417 \\
$\mathrm{TDS}$ & 3.801 & 0.0554 \\
$\mathrm{TN}$ & 3.695 & 0.0628 \\
$\mathrm{pH}$ & 3.653 & 0.0656 \\
$\mathrm{BOD}$ & 3.573 & 0.0712 \\
$\mathrm{COD}$ & 3.456 & 0.0793 \\
$\mathrm{TSS}$ & 2.647 & 0.135 \\
$\mathrm{TP}$ & 2.497 & 0.1453 \\
Phenol & 2.384 & 0.1531 \\
$\mathrm{CN}$ & 2.250 & 0.1624 \\
\hline
\end{tabular}

The parameters of the second group were of lower entropy, that is, lower uncertainty. Cyanide and phenol came from coke-making factories; their contractions were of $0.15-0.16 \mathrm{mg} / \mathrm{L}$. The high kurtosis of TSS was caused by tailing of its distribution curve due to heterogeneity of wastewaters including sedimentation of solid particles during physico-chemical analyses.

\subsection{Entropy Weighted Index}

The calculated entropy weights were used by us to construct the entropy weighted index and to characterize the wastewater composition. A similar approach has been already used for the ground water quality assessment $[26,27,31]$. This is a simple way to describe complex water systems by one parameter. On the similar principle, for example, soil quality index (SQI) composed from several soil composition indicators $(\mathrm{pH}, \mathrm{TN}, \mathrm{TP}$, cation exchange capacity, soil organic matter, etc.) has been successfully used for soil composition assessment [42,43]. An analogy with the SAW model, EWI was calculated for every sample i according to Equation (3). The difference $1-h_{j}$ is called the relative redundancy and can be interpreted as a degree of diversification of information provided $[15,16,18,25,30,44]$. In information theory, the entropy weights represent useful information on variables (parameters). In other words, the higher the entropy weight, the more useful information on the parameter and vice versa.

The EWI plot was constructed in order to demonstrate the temporal changes of wastewater composition during a year as shown in Figure 2. The samples were labeled according to their sequence of sampling, therefore the plot demonstrates their temporal composition changes. The EWI values were smoothed by the FFT algorithm by us to clearly see some trends in the data. In the first half of the year, the EWI values slightly increased during January and February and then oscillated around the mean (see the next paragraph) until a period between June and August. The minimal EWI value of 0.610 was reached at the end of July. In this period, people spend their time outside cities and production in some companies is reduced. In addition, higher temperatures accelerate chemical and biochemical processes in wastewaters. Conversely, during winter and autumn EWI increased due to the reduced migration of inhabitants and lower temperatures, which decelerated the chemical and biochemical processes in wastewaters. The EWI plot was compared with the plot of COD (Figure 3), which is the simple and typical wastewater parameter. Both plots were found to be similar as expected. 


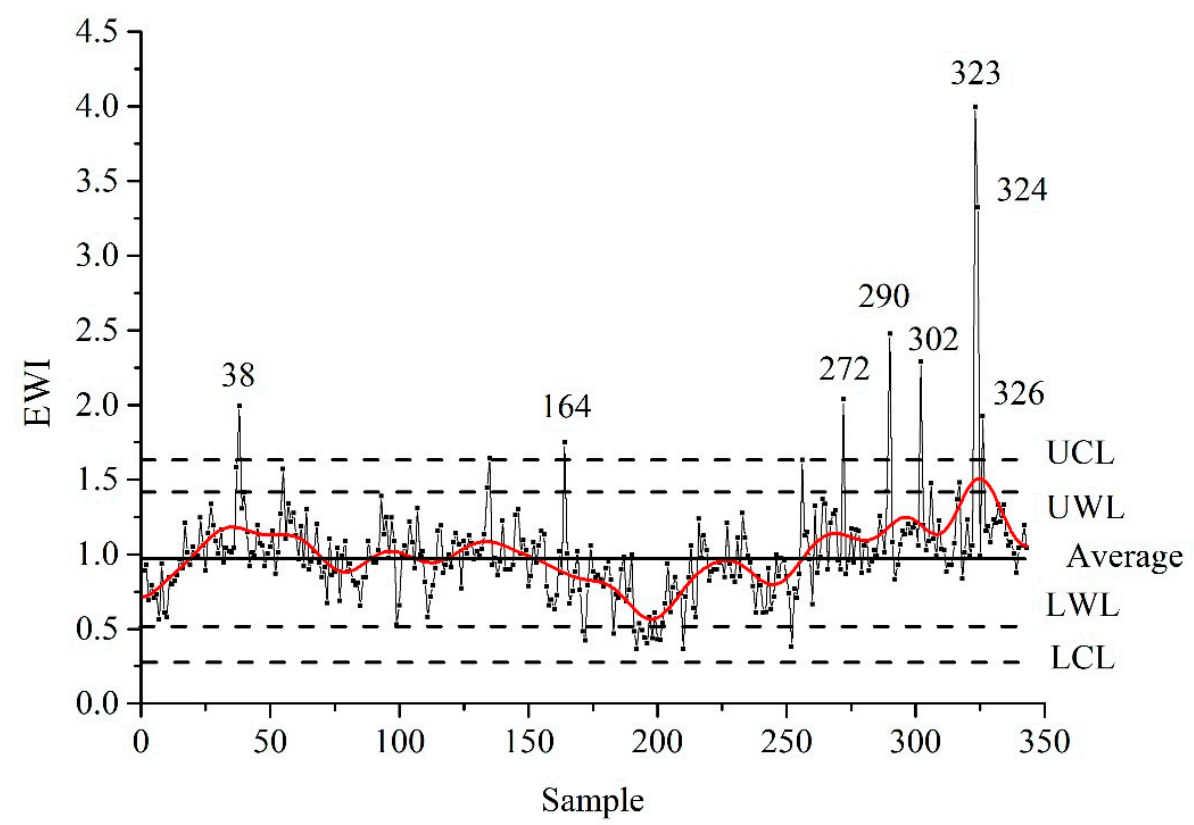

Figure 2. Entropy weighted index (EWI) plot of wastewaters during year. The labels identify the samples.

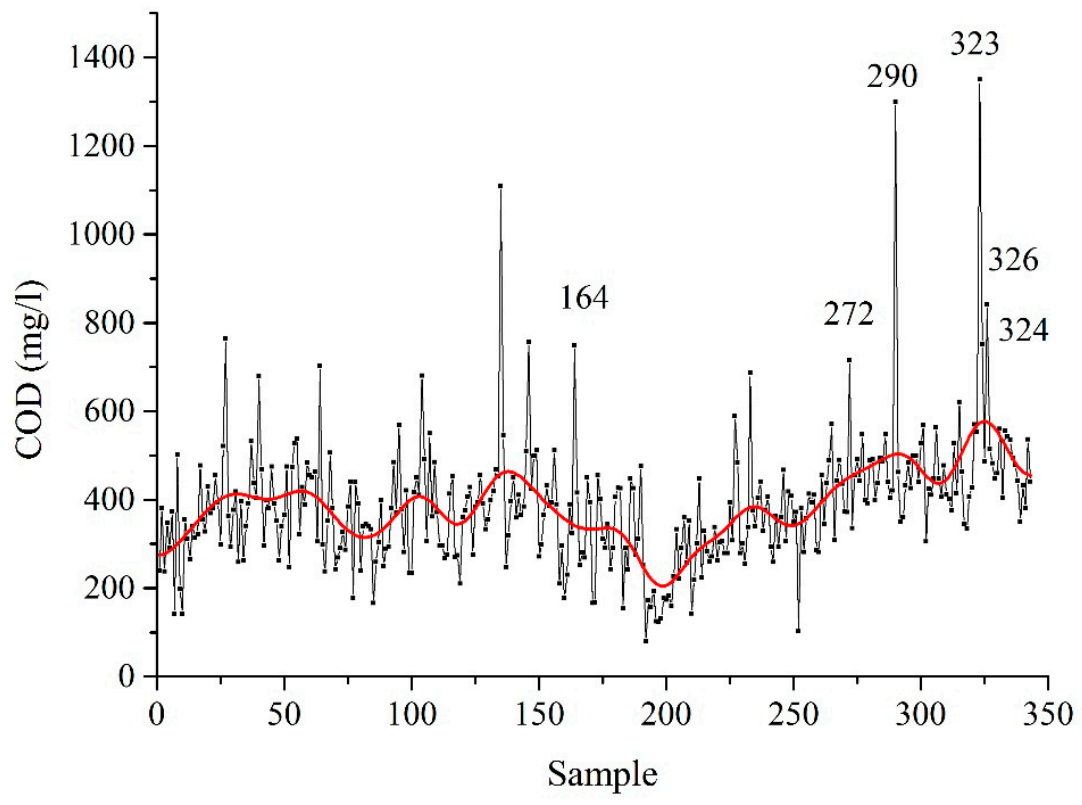

Figure 3. Chemical oxygen demand (COD) plot of wastewaters during year. The labels identify the samples.

\subsection{Statistical Analysis of EWI Data}

The EWI values were statistically processed by exploratory analysis and outlaying samples corresponding to EWI $\geq 1.65$ were identified: samples 38, 164, 272, 290, 302, 323, 324 and 326. The composition of the outliers is given in Table S1 (Supplementary Materials); the outlaying parameters detected by box-and-whisker plots were highlighted in bold. All the outliers were confirmed by means of the robust Mahalanobis distances calculated according to Equation (8). The cut-off limit was set at $\sqrt{\frac{2}{11,0.975}}=4.682$ for the $97.5 \%$ quantile.

The outlaying samples were excluded from the dataset and remaining 335 were tested for normality which was proved by D'Agostino, Kolmogorov-Smirnov and moment tests (kurtosis $=3.403$, 
skewness $=-0.110$ ). The EWI mean and standard deviation were calculated at 0.965 and 0.227 , respectively; the EWI median was 0.972 . The lower warning limit (LWL) and upper warning limit (UWL) were calculated at 0.511 and 1.419, respectively, and the lower control limit (LCL) and upper control limit (UCL) were calculated at 0.284 and 1.646, respectively (Figure 2). All these limits are commonly used for the statistical regulation of various processes and can be used for the regulation of the EWI values.

\subsection{Verification of EWI}

The principal component weighted index [32] was employed in order to verify the EWI data. RPCA was applied for this purpose. PCWI was defined as follows

$$
\text { PCWI }=\sum_{k=1}^{q} u_{k} t_{k}
$$

where $u_{k}$ stands for the weight of $k$-th principal component calculated as

$$
u_{k}=\frac{\lambda_{k}}{\sum_{k=1}^{q} \lambda_{k}}
$$

where $\lambda_{k}$ is the eigenvalue of $k$-th PC and $q$ is the number of selected principal components. The objectivity of PCWI is based on the following facts: (i) principal components are orthogonal and thus independent which is consistent with the SAW theory and (ii) the weights of principal components correspond to their eigenvalues expressing their importance. When all 11 principal components were used $(q=11)$ their weights were equal to their variabilities. The scree and cumulative plots are shown in Figure 4.

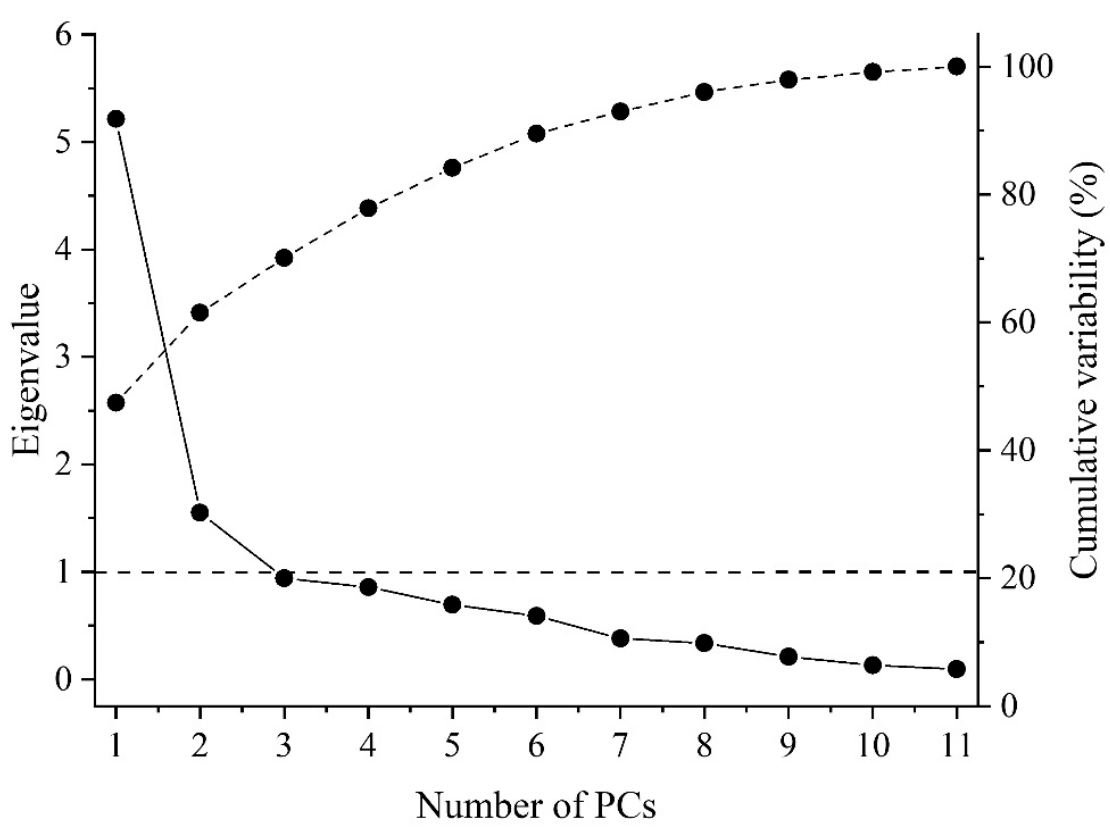

Figure 4. Cumulative and scree plots of principal components.

The significant linear correlation between EWI and PCWI $(r=0.910)$ is shown in Figure 5. It demonstrates a strong agreement between both indexes and confirms the validity of EWI. The outlaying samples $(38,164,272,290,302,323,324$ and 326) not included into the regression are 
also clearly visible. In addition, the scree plot indicated four main principal components and PCWI composed from them also correlated well with EWI: the correlation coefficient $r=0.900$.

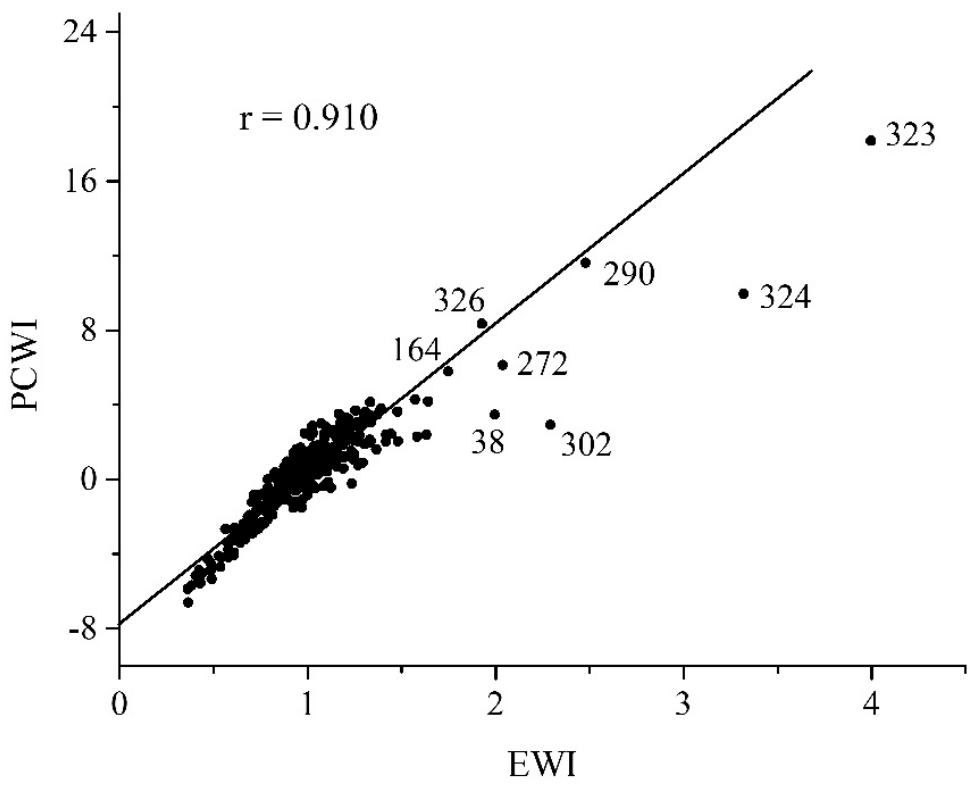

Figure 5. Linear regression between principal component weighted index (PCWI) and EWI.

\section{Conclusions}

The wastewater composition was evaluated using the Shannon entropy. Entropy of the wastewater parameters calculated based on their histograms decreased in the order: $\mathrm{PO}_{4}{ }^{3-}>\mathrm{NH}_{4}{ }^{+}>\mathrm{TDS}>\mathrm{TN}>$ $\mathrm{pH}>\mathrm{BOD}>\mathrm{COD}>\mathrm{TSS}>\mathrm{TP}>$ phenol $>\mathrm{CN}^{-}$. According to the entropy values the parameters were separated into two groups: (i) phosphate, ammonium, TDS, TN, pH, BOD and COD and (ii) TSS, TP, phenol and cyanide. The parameters from the first group should be monitored frequently because of their higher uncertainty in terms of the higher temporal changes.

The entropy weights were calculated by us to define the entropy weighted index analogous to the SAW model. The EWI plot showed the temporal changes of wastewater composition during one year. The EWI values were statistically analyzed by univariate statistics and the limits for statistical regulation, such as UCL, LCL, UWL and LWL, were calculated. In addition, the outlaying samples were detected by univariate and multivariate analyses. EWI was verified by comparison with PCWI composed from the robust principal components. EWI agreed well with PCWI which was documented with their correlation coefficient $r=0.910$ for all principal components and $r=0.900$ for four main ones.

The validation confirmed the capability of EWI to reliably characterize wastewater composition as the single indicator and could be of interest to BWWTP operators as well as other experts and decision makers in this field. The main advantage of EWI is the simple histogram-based calculation of entropy with no need of the normal distribution of the used parameters. Based on the results mentioned above one can conclude that information entropy is suitable for the evaluation of wastewater composition.

Supplementary Materials: The following are available online at http://www.mdpi.com/2073-4441/12/4/1095/s1, Figure S1: P-P plot of parameter entropies, Table S1: Composition of identified outlaying samples.

Funding: This work was financially supported by the projects "Institute of Environmental Technology-Excellent Research" (CZ.02.1.01/0.0/0.0/16_019/0000853) and Large Research Infrastructure ENREGAT (project No. LM 2018098) provided by the Ministry of Education, Youth and Sports of the Czech Republic. The author has no conflicts of interest to declare.

Conflicts of Interest: The author declares no conflicts of interest. The funders had no role in the design of the study; in the collection, analyses, or interpretation of data; in the writing of the manuscript, or in the decision to publish the results. 


\section{References}

1. Shannon, C.E. A mathematical theory of communication. Bell Syst. Tech. J. 1948, 27, 379-423. [CrossRef]

2. Dang, T.K.L.; Meckbach, C.; Tacke, R.; Waack, S.; Gültas, M.A. Novel Sequence-Based Feature for the Identification of DNA-Binding Sites in Proteins Using Jensen-Shannon Divergence. Entropy 2016, 18, 13. [CrossRef]

3. Maruyama, T.; Kawachi, T.; Singh, V.P. Entropy-based assessment and clustering of potential water resources availability. J. Hydrol. 2005, 309, 104-113. [CrossRef]

4. Tsallis, C. Approach of Complexity in Nature: Entropic Nonuniqueness. Axioms 2016, 5, 20. [CrossRef]

5. Chamberlin, R. The Big World of Nanothermodynamics. Entropy 2014, 17, 52-73. [CrossRef]

6. Barigye, S.J.; Marrero-Ponce, Y.; Perez-Gimenez, F.; Bonchev, D. Trends in information theory-based chemical structure codification. Mol Divers 2014, 18, 673-686. [CrossRef]

7. Eckschlager, K.; Štěpánek, V.; Danzer, K. A review of information theory in analytical chemometrics. J. Chemom. 1990, 4, 195-216. [CrossRef]

8. Farhadinia, B. Information measures for hesitant fuzzy sets and interval-valued hesitant fuzzy sets. Inf. Sci. 2013, 240, 129-144. [CrossRef]

9. Gültas, M.; Haubrock, M.; Tüysüz, N.; Waack, S. Coupled mutation finder: A new entropy-based method quantifying phylogenetic noise for the detection of compensatory mutations. BMC Bioinform. 2012, 13, 225. [CrossRef]

10. Martin, L.C.; Gloor, G.B.; Dunn, S.D.; Wahl, L.M. Using information theory to search for co-evolving residues in proteins. Bioinformatics 2005, 21, 4116-4124. [CrossRef]

11. Guido, R.C. A tutorial review on entropy-based handcrafted feature extraction for information fusion. Inf. Fusion 2018, 41, 161-175. [CrossRef]

12. Oguz, I.; Cates, J.; Datar, M.; Paniagua, B.; Fletcher, T.; Vachet, C.; Styner, M.; Whitaker, R. Entropy-based particle correspondence for shape populations. Int. J. Comput. Assist. Radiol. Surg. 2016, 11, 1221-1232. [CrossRef] [PubMed]

13. Ijadi Maghsoodi, A.; Abouhamzeh, G.; Khalilzadeh, M.; Zavadskas, E.K. Ranking and selecting the best performance appraisal method using the MULTIMOORA approach integrated Shannon's entropy. Front. Bus. Res. China 2018, 12. [CrossRef]

14. Tsallis, C. Economics and Finance: Q-Statistical Stylized Features Galore. Entropy 2017, 19, 457. [CrossRef]

15. Wang, Q.; Wu, C.; Sun, Y. Evaluating corporate social responsibility of airlines using entropy weight and grey relation analysis. J. Air Transp. Manag. 2015, 42, 55-62. [CrossRef]

16. Shemshadi, A.; Shirazi, H.; Toreihi, M.; Tarokh, M.J. A fuzzy VIKOR method for supplier selection based on entropy measure for objective weighting. Expert Syst. Appl. 2011, 38, 12160-12167. [CrossRef]

17. Zhang, Y.; Yang, Z.; Li, W. Analyses of urban ecosystem based on information entropy. Ecol. Model. 2006, 197, 1-12. [CrossRef]

18. Delgado, A.; Romero, I. Environmental conflict analysis using an integrated grey clustering and entropy-weight method: A case study of a mining project in Peru. Environ. Model. Softw. 2016, 77, 108-121. [CrossRef]

19. Kawachi, T.; Maruyama, T.; Singh, V.P. Rainfall entropy for delineation of water resources zones in Japan. J. Hydrol. 2001, 246, 36-44. [CrossRef]

20. Singh, V.P. Entropy Theory and its Application in Environmental and Water Engineering; John Wiley \& Sons, Ltd.: Hoboken, NJ, USA, 2013; p. 642.

21. Frank, B.; Pompe, B.; Schneider, U.; Hoyer, D. Permutation entropy improves fetal behavioural state classification based on heart rate analysis from biomagnetic recordings in near term fetuses. Med. Biol. Eng. Comput. 2006, 44, 179-187. [CrossRef]

22. Güçlü, B. Maximizing the entropy of histogram bar heights to explore neural activity: A simulation study on auditory and tactile fibers. Acta Neurobiol. Exp. 2005, 65, 399-407.

23. Hasson, U. The neurobiology of uncertainty: Implications for statistical learning. Philos. Trans. R. Soc. Lond. B Biol. Sci. 2017, 372. [CrossRef] [PubMed]

24. Grupp, H. The concept of entropy in scientometrics and innovation research. Scientometrics 1990, 18, $219-239$. [CrossRef] 
25. Zhang, Y.; Qian, Y.; Huang, Y.; Guo, Y.; Zhang, G.; Lu, J. An entropy-based indicator system for measuring the potential of patents in technological innovation: Rejecting moderation. Scientometrics 2017, 111, 1925-1946. [CrossRef]

26. Islam, A.; Ahmed, N.; Bodrud-Doza, M.; Chu, R. Characterizing groundwater quality ranks for drinking purposes in Sylhet district, Bangladesh, using entropy method, spatial autocorrelation index, and geostatistics. Environ. Sci. Pollut. Res. Int. 2017, 24, 26350-26374. [CrossRef]

27. Gorgij, A.D.; Kisi, O.; Moghaddam, A.A.; Taghipour, A. Groundwater quality ranking for drinking purposes, using the entropy method and the spatial autocorrelation index. Environ. Earth Sci. 2017, 76. [CrossRef]

28. Shyu, G.S.; Cheng, B.Y.; Chiang, C.T.; Yao, P.H.; Chang, T.K. Applying factor analysis combined with kriging and information entropy theory for mapping and evaluating the stability of groundwater quality variation in Taiwan. Int. J. Environ. Res. Public Health 2011, 8, 1084-1109. [CrossRef]

29. An, Y.; Zou, Z.; Li, R. Water quality assessment in the Harbin reach of the Songhuajiang River (China) based on a fuzzy rough set and an attribute recognition theoretical model. Int. J. Environ. Res. Public Health 2014, 11,3507-3520. [CrossRef]

30. Wu, J.; Li, P.; Qian, H.; Chen, J. On the sensitivity of entropy weight to sample statistics in assessing water quality: Statistical analysis based on large stochastic samples. Environ. Earth Sci. 2015, 74, 2185-2195. [CrossRef]

31. Wu, J.; Peiyue, L.; Hui, Q. Groundwater Quality in Jingyuan County, a Semi-Humid Area in Northwest China. E J. Chem. 2011, 8. [CrossRef]

32. Praus, P. Principal Component Weighted Index for Wastewater Quality Monitoring. Water 2019, 11, 2376. [CrossRef]

33. Hwang, C.L.; Yoon, K. Multiple Attribute Decision Making; Springer: Berlin/Heidelberg, Germany, 1981; p. 269.

34. Wold, S.; Esbensen, K.; Geladi, P. Principal component analysis. Chemom. Intell. Lab. Syst. 1987, 2, 37-52. [CrossRef]

35. Praus, P. Water quality assessment using SVD-based principal component analysis of hydrological data. Water Sa 2005, 31, 417-422. [CrossRef]

36. Praus, P. SVD-based principal component analysis of geochemical data. Cent. Eur. J. Chem. 2005, 3, 731-741. [CrossRef]

37. Hubert, M.; Debruyne, M. Minimum covariance determinant. Comput. Stat. 2009, 2, 8. [CrossRef]

38. Rousseeuw, P.J.; Driessen, K.V. A Fast Algorithm for the Minimum Covariance Determinant Estimator. Technometrics 1999, 41, 212-223. [CrossRef]

39. Hubert, M.; Rousseeuw, P.J.; Vanden Branden, K. ROBPCA: A New Approach to Robust Principal Component Analysis. Technometrics 2005, 47, 64-79. [CrossRef]

40. Verboven, S.; Hubert, M. LIBRA: A MATLAB library for robust analysis. Chemom. Intell. Lab. Syst. 2005, 75, 127-136. [CrossRef]

41. Yeoman, S.; Stephenson, T.; Lester, J.N.; Perry, R. The removal of phosphorus during wastewater treatment. A review. Environ. Pollut. 1988, 49, 183-233. [CrossRef]

42. Yu, P.; Liu, S.; Zhang, L.; Li, Q.; Zhou, D. Selecting the minimum data set and quantitative soil quality indexing of alkaline soils under different land uses in northeastern China. Sci. Total Environ. 2018, 616, 564-571. [CrossRef]

43. Li, P.; Zhang, T.; Wang, X.; Yu, D. Development of biological soil quality indicator system for subtropical China. Soil Tillage Res. 2013, 126, 112-118. [CrossRef]

44. Lotfi, F.H.; Fallahnejad, R. Imprecise Shannon's Entropy and Multi Attribute Decision Making. Entropy 2010, 12, 53-62. [CrossRef]

(C) 2020 by the author. Licensee MDPI, Basel, Switzerland. This article is an open access article distributed under the terms and conditions of the Creative Commons Attribution (CC BY) license (http://creativecommons.org/licenses/by/4.0/). 